\title{
THE IMPACT OF IMPLEMENTING A SYSTEM APPROACH TO QUALITY: A GENERAL CONTRACTOR CASE STUDY
}

\author{
Elizabeth Gordon ${ }^{1}$, Keila Rawlinson ${ }^{2}$, Ebrahim Eldamnhoury ${ }^{3}$, Marton \\ Marosszeky $^{4}$, and Dean Reed ${ }^{5}$
}

\begin{abstract}
This paper introduces a novel General Contractor approach to quality management called the Systems Approach to Quality (SAQ), which shares the Behavior-Based Quality (BBQ) concern for individual initiative and responsibility, and Quality Function Deployment (QFD) principles. Building on that previous work, this paper investigates the quantitative and cultural impacts of implementing a company's SAQ approach in its construction projects across the U.S. To do so, the authors examine lagging indicators of various performance areas including cost, schedule, quality, safety, and changes for a group of projects that implemented the SAQ approach and compare them to another group of projects that did not. The hypothesis under investigation is that SAQ implementation in projects improves performance across a range of critical indicators. Furthermore, the study compares project culture in projects where SAQ was implemented to those where it was not using Quinn's Competing Values Framework (CVF). The early results from this work indicate that the implementation of an approach such as SAQ leads to significant financial and non-cost benefits including improved collaboration.
\end{abstract}

\section{KEYWORDS}

Action learning, complexity, process, waste, collaboration, trust, system approach, quality function deployment (QFD), performance metrics, quinn competing values.

\section{INTRODUCTION}

Rework is a substantial risk in the construction industry due to its significant repercussions on other critical aspects of construction performance such as schedule, cost, quality, profitability, and safety (Love et al. 2016). Love et al. (2020) define construction rework as "wasteful and non-value-adding activity in correcting efforts and fixing defects resulting in variation in the scope of work." According to the Construction Industry

\footnotetext{
1 Quality Leader, DPR Construction, San Francisco, CA 94111, USA, +1 650 339-9588, ElizabethG@dpr.com, orcid.org/0000-0001-8165-0459

2 Operations Data Analyst, DPR Construction, Denver, CO 80112, USA, +1 303 349-083, KeilaR@dpr.com, orcid.org/0000-0001-9718-5483

3 Business Process Analyst, DPR Construction, San Francisco, CA 94111, USA, +1 6504749057 , Ebrahime@dpr.com, orcid.org/0000-0001-7980-1246

4 Managing Director, Marosszeky Associates P.L., Mandalong NSW 2264, Australia, marton@marosszekyassociates.com, orcid.org/0000-0002-5774-126X

5 Owner and Consultant, Capability-Building, Santa Cruz, CA 95060, USA, Dean@deansreed.com, orcid.org/0000-0002-2916-8558
} 
Institute (CII), direct costs in the US caused by rework average 5\% of total construction costs (CII 2005). In Australia, Marosszeky and Thomas (2002) reported a detailed study that costed 3500 rework items on $\$ 60$ million of construction across four projects and found it to be $6.5 \%$ of construction cost. In addition, Love (2002) indicated that, on average, rework contributes up to $52 \%$ of the total growth of incurred costs and can increase schedule overruns by $22 \%$. Based on the CII study, considering that $\$ 1.75$ trillion was spent on construction in the US in 2017, almost $\$ 87$ billion was wasted on rework.

The industry's longstanding view of rework causation mainly focuses on individual behavior, adopting the traditional "blame the perpetrator" approach (Bertelsen 2003). In this view, the cause of rework is fully explained by individuals' bad judgments, inaccurate assessments, or violations. This approach assumes that management systems are inherently sound, linear, and only the unreliability of individuals creates rework. However, organizations are non-linear interconnected sub-systems that encompass various levels of complexity. Saurin et al. (2013) describes a complex system as a system that has: (1) large number of dynamically interacting elements; (2) wide diversity of elements; (3) unanticipated variability; and (4) resilience. While an individual's unreliability can partially contribute to errors, it is a symptom of a deeper problem within the system that stems from multiple causes and dynamic complexity. It is impossible to separate systematic management of the workplace and the behavior of an individual within a system. Dekker (2017) shows that a more accurate explanation for errors can be found by finding how an individual's actions and behaviors made sense at the time given the circumstances within their environment. From this view of causation, an employee's behavior alone cannot be blamed for a quality failure. Viewing quality through a complex-system perspective, and accounting for environmental pressures, unruly technology, and social processes within an organization leads to a more robust and plausible understanding of quality management.

This means that the responsibility for quality performance within complex systems rests with the management system as well as the behavior of employees within it. This dynamic between management system factors that influence an individual's behavior and how the individual responds can also be described as team culture. The SAQ systems approach described in this paper recognizes the system complexity within which employees operate through trade-offs; it builds from available knowledge to identify Distinguishing Features of Work (DFOW), understands stakeholders' critical requirements; aligns expectations prior to starting work and tracks measurable criteria as the work is delivered. In addition, it recognizes that promoting healthy behavioral practices can improve overall quality performance within an organization. This includes upfront, honest conversations amongst team members and with different stakeholders to create psychological safety that encourages questioning and discussion.

\section{A SYSTEM APPROACH TO QUALITY}

In a 2018 paper (Spencley et al. 2018), the approach to quality management developed by a major US builder was described as a Behavior Based Quality (BBQ) approach. That paper referenced the similarity of elements of the company's BBQ approach to Quality Function Deployment (QFD). In hindsight, the authors believe the label is not accurate, that it should be seen as a systems approach.

The approach was described as recognizing upstream requirements, information packaging, mindsets, behaviors, practices, and information gaps that result in quality issues and unpredictable results downstream in the production process. It is a method in 
which client, design team, and construction stakeholders share their expectations, knowledge, experience and agree on Distinguishing Features of Work (DFOW), Measurable Acceptance Criteria (MAC) for each work package, resulting in better project outcomes. It was argued that quality management must require accountable project stakeholders from the owner's team, design team, GC's team, and Trade partners' teams to explore, discuss, and eventually agree on the requirements that are to be met, rather than simply checking quality to ensure compliance. It was argued that quality management should focus on the role of individuals' behaviors and demonstrate an understanding of people's roles throughout the project lifecycle from pursuit through closeout: what do stakeholders (those providing the deliverable, the supplier and those receiving the deliverable, the customers) want, know, and believe should be done. It is crucial to acknowledge that individuals operate within an ever-changing complex system, and to improve quality performance, systems-focused adaptive approaches need to be implemented.

QFD is a powerful systems-approach that interprets the design requirements of the client into terms that trade contractors understand. This process is used to translate users' needs into critical product characteristics and specific measurable criteria that can be incorporated early in the design stage (Alarcon and Mardones 1998). A QFD system can be realized through (1) ensuring consistency between customer requirements and product's measurable criteria, (2) converting consumer's demands into major quality assurance milestones or "Points of Release" throughout the project lifecycle, (3) ensuring consistency between the design phase and construction work, and (4) optimizing the integration of consumer's perceptions and other aspects that can affect project outcomes (Gargione 1999).

\section{SAQ DEVELOPMENT AND CHARACTERISTICS}

In this paper, the same approach is reinterpreted as a Systems Approach to Quality (SAQ), recognizing that the approach is much more than a behavior-based approach. Rodney Spencley, the architect of the SAQ approach, came into a senior quality leadership role after successfully implementing a behavior-based safety (BBS) approach within the company. He ensured that the importance of individual responsibility (for safety outcomes) was incorporated into the company's approach to quality. Although developed independently of QFD, the SAQ approach has similar characteristics to QFD. Saurin et al. (2013) identified six guidelines for the management of complex socio-technical systems like construction including: (1) giving visibility to processes and outcomes; (2) encouraging diversity of perspectives when making decisions; (3) anticipating and monitoring the impact of small changes; (4) Understanding the gap between prescription and practice; (5) and creating an environment that supports resilience. To this extent, SAQ emerged as an organic response to customer-initiated quality challenges facing the business, while at the same time it recognized the complex nature of projects.

This homegrown SAQ also recognizes the importance of having healthy individual behaviors including open lines of communications, measurable collaboration, and psychological safety, which is synergetic with SAQ. Spencley et al. 2018 describes how the model is based on 1)- unifying language and perspectives among different stakeholders; 2)- understanding expectations and best work practices; and 3)- developing objective measurable acceptance criteria for the end product and the processes and deliverables to achieve the end product. Table 1 summarizes the characteristics and workflows of the model that was further developed after coaching hundreds of different 
projects from $1 \mathrm{M}$ to $5 \mathrm{~B}$ across the U.S. over many decades. Each project was experiencing different variations of stakeholder engagement, stakeholder availability and capability, supply chain variability and site working conditions. These experiences reflect Bertelsen (2003) conclusion "that construction is indeed a complex, nonlinear and dynamic phenomenon, which often exists on the edge of chaos." Knowing that every project experience unpredictability and different levels of variability, these characteristics and workflows were developed to help clarify and prioritize what teams should focus on to set themselves up for the greatest likelihood of reliable outcomes.

Table 1: GC Systems Approach to Quality

\begin{tabular}{|c|c|}
\hline Principle & Implementation \\
\hline $\begin{array}{l}\text { Build from } \\
\text { Knowledge \& } \\
\text { Information }\end{array}$ & $\begin{array}{l}\text { Project teams start with the project information and a working } \\
\text { understanding of what others have learned and identified as } \\
\text { Distinguishing Features of Work (DFOW). DFOW are those features of } \\
\text { a product and the processes necessary to create it, that require } \\
\text { increased attention to achieve the intended result. }\end{array}$ \\
\hline Points of Release & $\begin{array}{c}\text { Project teams also identify key Points of Release (POR) in the project } \\
\text { life cycle. A POR can be a project milestone, importantly it reflects that } \\
\text { work will be released to the next phase. This is a critical gate in the } \\
\text { workflow. Work should be assessed as ready for release before it is } \\
\text { masked by new work. }\end{array}$ \\
\hline $\begin{array}{l}\text { Understand } \\
\text { Expectations } \\
\text { (DFOW) }\end{array}$ & $\begin{array}{l}\text { The entire project team and supply chain must understand the vision of } \\
\text { no surprises and predictable outcomes. Engaging the team starts with } \\
\text { the First Planners and understanding their DFOW. First Planners are } \\
\text { those project stakeholders accountable for delivering the project goals. } \\
\text { Based on the project POR, there is a process to engage team members } \\
\text { in understanding the organizational and personal commitments needed } \\
\text { to achieve this vision. As new stakeholders: the owner; end-user } \\
\text { designers; fabricators; builder; trade partners; Authority Having } \\
\text { Jurisdiction (AHJ) and other decision makers accountable for project } \\
\text { results on-board, they are engaged in this process. }\end{array}$ \\
\hline $\begin{array}{l}\text { Align Teams to } \\
\text { Measurable } \\
\text { Acceptance } \\
\text { Criteria (MAC) }\end{array}$ & $\begin{array}{l}\text { The process of aligning the team Measurable Acceptance Criteria (MAC) } \\
\text { involves accountable stakeholders communicating and aligning on } \\
\text { expectations for the POR. Numerous deliverables and workflows provide } \\
\text { information for each POR. For each phase of the project, stakeholders } \\
\text { firstly identify DFOW and risk specific to key deliverables and secondly, } \\
\text { define MAC and clear commitments to achieve them. Visual controls } \\
\text { show whether conversations are happening in the right time frame, with } \\
\text { the right stakeholders and result in the documented MAC. }\end{array}$ \\
\hline $\begin{array}{l}\text { Evaluate } \\
\text { Delivered } \\
\text { Product }\end{array}$ & $\begin{array}{l}\text { At the identified POR, deliverables are evaluated against the agreed to } \\
\text { MAC. When work does not meet the MAC, those involved in the work } \\
\text { investigate the breakdowns in the work process through cause-mapping. } \\
\text { Leaders develop a strategy to mitigate the situation. }\end{array}$ \\
\hline $\begin{array}{l}\text { Building the } \\
\text { project } \\
\text { knowledge base }\end{array}$ & $\begin{array}{l}\text { Now understanding the breakdowns in the work processes, the team } \\
\text { reflects on what they have learned, records it in the form of lessons, and } \\
\text { shares their learning within the project as well as their organizations. }\end{array}$ \\
\hline
\end{tabular}

\section{The IMPaCt OF SAQ on Project SucCess}

This study aimed to evaluate the effect of implementing the SAQ approach on performance in relation to cost, schedule, safety, quality, and change. The scope of the study involved a quantitative assessment of the performance of a group of projects that 
implemented SAQ (Intervention Group) and compared their outcomes to a similar group of projects that did not (Control Group). The goal was to identify if projects that adopted the SAQ approach had any advantages. All the projects were completed in the past 5 years. The specific quantitative performance areas and metrics were selected to be consistent with data availability and the company's internal critical success factors. Table (2) lists the investigated performance areas and the corresponding performance metrics and units of measurement.

The two sample groups were designed to be similar and to be representative of the company's business in terms of project type and geographic reach. Data was collected from 22 projects, $60 \%$ were GMP, and $40 \%$ were lump sum, $36 \%$ of the projects were advanced technology, $27 \%$ were higher education, $18 \%$ were commercial, $9 \%$ were healthcare, and $9 \%$ other. The combined, total dollar amount of construction work for the studied projects was around $\$ 3.5$ billion, with an average cost of around $\$ 162$ million per project. The sample groups were similar in total value. Table 2 shows the various performance metrics that were studied and their units of measurements.

Table 2: Performance Metrics and Unit of Measure

\begin{tabular}{|c|c|c|c|}
\hline Area & Metric & Formula & $\begin{array}{l}\text { Unit of } \\
\text { Measure }\end{array}$ \\
\hline \multirow[t]{3}{*}{ Cost } & Cost Growth & $\frac{\text { Actual Cost - Intial (Anticipated)Cost }}{\text { Intial Cost }}$ & $\begin{array}{c}\text { Percentage } \\
\text { of the total } \\
\text { cost }\end{array}$ \\
\hline & \multirow[t]{2}{*}{ Fee Gain } & Fee Erosion + Fee Gain + Nonreimbusrables & \multirow{2}{*}{$\begin{array}{l}\text { Percentage } \\
\text { of total fee }\end{array}$} \\
\hline & & $\overline{\text { Contract Fee(Current - Appraoved Fee for changes }}$, & \\
\hline \multirow[t]{4}{*}{ Schedule } & Schedule & SC at Trend (Actual) - SC at Mbilization & \multirow{2}{*}{$\begin{array}{c}\text { Percentage } \\
\text { of the total } \\
\text { duration }\end{array}$} \\
\hline & $\begin{array}{l}\text { Growth from } \\
\text { Mobilization }\end{array}$ & Actual SC - Actual Mobilization & \\
\hline & \multirow{2}{*}{$\begin{array}{l}\text { Change } \\
\text { percent } \\
\text { duration }\end{array}$} & Ave. Potential Change Items (PCI)Processing Time & \multirow{2}{*}{$\begin{array}{c}\text { Percentage } \\
\text { of total } \\
\text { duration }\end{array}$} \\
\hline & & Actual Construction Duration & \\
\hline \multirow{2}{*}{$\begin{array}{c}\text { Change } \\
\text { Manage- } \\
\text { ment }\end{array}$} & Value of & Total Value of Change Orders & \multirow{2}{*}{$\begin{array}{c}\text { Percentage } \\
\text { of the total } \\
\text { cost }\end{array}$} \\
\hline & $\begin{array}{l}\text { Percent } \\
\text { Changes }\end{array}$ & $\overline{\text { Actual Contract Cost (Revised) }}$ & \\
\hline \multirow{2}{*}{ Safety } & Incidents per & Number of Incidents & \multirow{2}{*}{$\begin{array}{l}\text { Number per } \\
\text { million } \\
\text { dollars }\end{array}$} \\
\hline & $\$ 100 \mathrm{M}$ & $\$ \$ 100 M$ & \\
\hline \multirow[t]{2}{*}{ Quality } & Value of & Order of Magnitude of Reported Claims & \multirow{2}{*}{$\begin{array}{c}\text { Percentage } \\
\text { of the total } \\
\text { cost }\end{array}$} \\
\hline & $\begin{array}{l}\text { reported } \\
\text { Claims }\end{array}$ & $\begin{array}{c}\text { Total Contract Cost } \\
\end{array}$ & \\
\hline
\end{tabular}

The comparison also involved an assessment of project culture using Quinn's Competing Values Framework (CVF) for both groups. The assessment of project culture was important as the SAQ approach had been designed to change team culture towards one of collaboration in terms of behaviors and information sharing. The CVF is designed to assess and characterize the cultural orientation of a team or company (Cameron and Quinn 2011). The CVF is based on the hypothesis that the culture of every organization can be characterized in terms of four basic orientations, pairs of which are in tension with each other. On one axis the tension is between collaborate (clan) and compete (market) behaviors, while on the other the tension is between control (hierarchy) and create 
(adhocracy). The characteristics of teams on the collaborate-compete axis are relatively easily understood in terms of teamwork, trust, openness, and flexibility. But, on the control-create axis, the characteristics in tension are less obvious. The control bias reflects a belief that processes can be codified, learned, and simply need to be repeated, whereas the create bias reflects a belief that teams operate in more complex and variable environments where they also need the ability to agilely solve unexpected problems.

CVF has been tested on thousands of organizations and has been found to provide a robust scientific approach, it also leads to recommendations for how to improve individual and organizational performance (Cameron and Quinn 2011). The assessment is based on a representative set of team members answering questions in relation to six aspects of organizational culture: dominant characteristics, organizational leadership, management of employees, organizational glue, strategic emphases, and criteria of success. Respondents select from four descriptors in relation to each aspect by dividing 100 points between the four alternatives provided. The selection is made to describe the existing status as well as a desired future state if greater success were to be achieved. The framework provides a basis for gaining an improved understanding of the basic elements of culture and provides some insight into how the culture can be changed.

\section{ANALYSIS}

\section{Cultural Study}

The research team distributed surveys to three key members of each of the project's teams involved in both groups of projects. Twenty-two valid responses were collected from the Intervention Group and 18 valid responses were collected from Control Group. Invalid responses were rejected, also, several key team members who had been involved in projects had left the company and could not be contacted. Going forward, it was proposed to survey project teams during the project lifecycle. Figure 1 shows the cultural biases of the project teams for Intervention and Control projects during the project and the culture shift they would like to see to improve outcomes. The data was also aggregated according to the roles of the respondent (i.e., Superintendents, Project Managers (PM), Project Engineers (PE). This allowed the researchers to identify the different cultural perceptions of team members in different roles on projects.

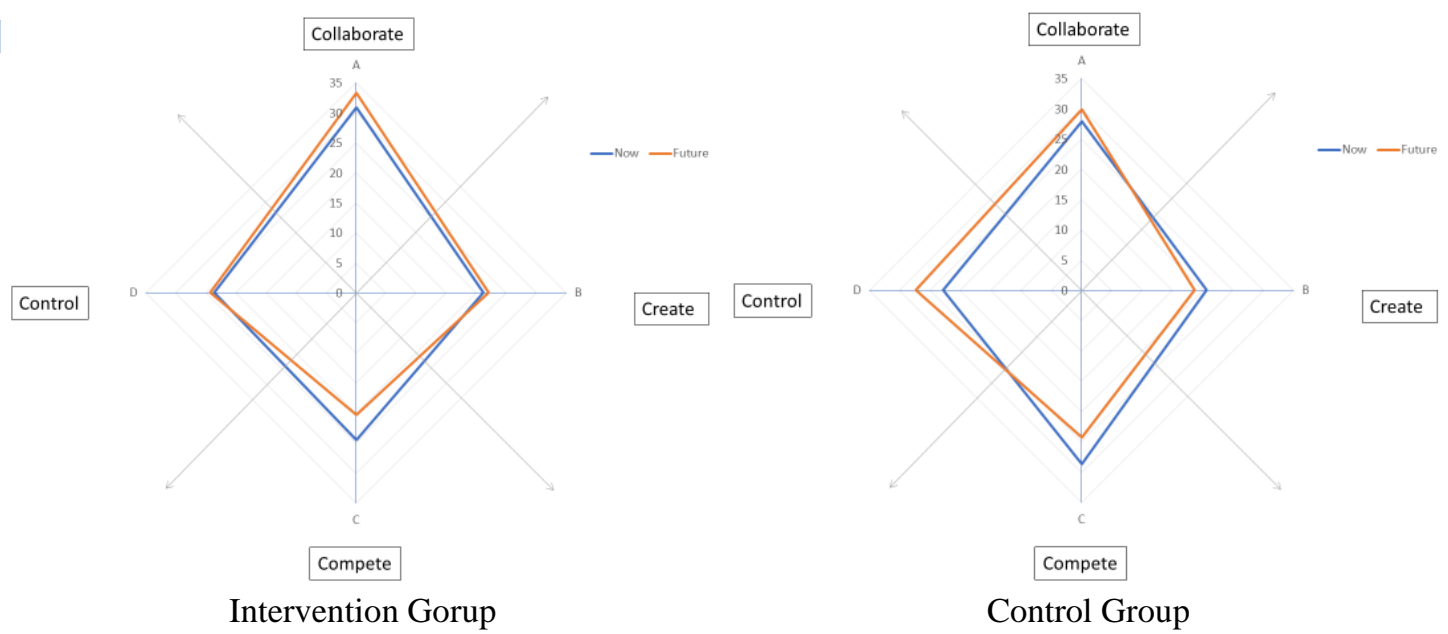

Figure 1: Assessment of Projects’ Teams Culture Shift 
On the Collaborate-Compete axis, Intervention Group teams perceived their culture to be significantly skewed toward collaboration relative to Control Group teams. Both groups wanted slightly more collaboration in the future than at the present.

On the Control-Create axis, Control Group respondents perceived that they have a higher level of control relative to create and perceived the need for a further increase in control in the future at the expense of create. Intervention Group respondents perceived a balance between control and create and did not see a need to change that balance.

Control Group PMs perceived site culture to be more competitive than do Intervention Group PEs who perceived it to be significantly more collaborative. This may be due to the nature of the PM's job and their accountability for meeting cost and schedule constraints while PEs see much more collaboration because they are coordinating meetings with different stakeholders to work through construction issues. In the future, the Intervention Group PMs wanted to significantly decrease competition, and to see an increase in creation on projects.

\section{QUANTITATIVE STUDY}

To identify the impact of SAQ on key performance areas (i.e., cost, schedule, safety, change management, quality management) a comparison of Intervention Group and Control Group projects was conducted based on these metrics. Table 3 summarizes the comparison across the 2 groups of projects.

Table 3: Performance Metrics Medians

\begin{tabular}{cccc}
\hline $\begin{array}{c}\text { Performance } \\
\text { Area }\end{array}$ & Performance Metric & \multicolumn{2}{c}{ Median } \\
\hline & Cost Growth & $\begin{array}{c}\text { Intervention } \\
\text { group }\end{array}$ & $\begin{array}{c}\text { Control } \\
\text { group }\end{array}$ \\
Cost & Fee Gain & $5 \%$ & $9 \%$ \\
Schedule & Schedule Growth at Mobilization & $4 \%$ & $-35 \%$ \\
Change & Change Percent Duration & $11 \%$ & $18 \%$ \\
Management & Value of Percent Changes & $14 \%$ & $18 \%$ \\
Safety & Incidents per $\$ 100 \mathrm{M}$ & $5 \%$ & $13 \%$ \\
Quality & Value of Claims as a Percentage of & 1.5 & 1.9 \\
\hline
\end{tabular}

\section{Cost Performance}

The researchers examined the cost performance of both groups of projects using two metrics: Cost Growth and Fee Gain. Both metrics show very significantly improved and more predictable performance when SAQ is implemented.

\section{Schedule Performance}

The researchers examined the schedule performance of both groups of projects using Schedule Growth from Mobilization, which is the difference between the substantial completion date forecasted at mobilization and the actual substantial completion date 
achieved. This metric indicates the effectiveness of schedule management during construction, and it was found that Intervention Group projects had significantly less Schedule Growth.

\section{Change Management Performance}

Change Management Performance was examined by measuring two metrics: Change Percent Duration and the Value of Percent Changes. Both metrics indicate that Intervention Group projects performed significantly better as the extent of change was substantially lower and more predictable.

\section{Quality Performance through Evaluation of Claims}

To evaluate whether project teams could manage expectations with predictable results, the cost of claims reported by each group was reviewed. These costs included uninsured and insured property damage claims during the project and construction defect claims during the project and after the project. Construction defect latent claims can be reported up to 10 years after project completion. These claim costs do not represent all the rework costs incurred in a project, only the claim costs reported to the GC's internal risk group. Teams can also manage property damage and construction defect claims within the project budget and without reporting claims to the risk teams. These two factors help to explain why the cost of claims on these projects is significantly lower than industry standards. Of the two groups, Control Group projects had a higher reported amount of cost associated with the claims.

\section{Safety Performance}

No significant difference was observed in overall safety performance between the Intervention and Control Groups projects. What became obvious in the analysis was that a small number of projects (fewer than 20\%) had a disproportionate impact on the overall safety results. Closer examination revealed that on projects that were run by "recently recruited" project team leaders, poorer safety outcomes were achieved.

\section{DISCUSSION AND CONCLUSION}

Performance data was collected from 22 projects about cost, schedule, safety, quality, and changes. The projects were divided into two comparable groups, those that implemented SAQ and those that did not (the Control Group). Projects that implemented SAQ generally performed significantly better against a range of cost, schedule, and quality outcome metrics and had outcomes more consistent with the goals.

Across all standard project performance measures, the SAQ projects share two distinct advantages. First, results were more predictable as the performance outcomes were more closely aligned with the project targets. Second, SAQ projects have significantly improved results in all the dimensions that were assessed, higher profitability, better cost predictability, and improved schedule achievement.

Overall, wherever SAQ was deployed, trade partners and internal stakeholders were encouraged to have more and earlier conversations to facilitate planning, and to engage more closely to build a more collaborative project culture. There was also a focus on developing clearer contract language to describe customer objectives. SAQ appears to have facilitated better design with earlier stakeholder engagement to improve the outcomes of risk management plans by eliminating subsequent changes.

In addition, Quinn's CVF model was used to measure the cultural orientation of the two groups of projects. The study of culture was limited to three participants from each 
project, and even this was not achieved on some. People in three key roles were surveyed, PMs, PEs and Superintendents, and the assessments of participants in each group were aggregated.

The culture on projects where SAQ had been implemented was perceived to be more collaborative, less competitive, and more creative. Interestingly, on projects that did not deploy SAQ, it was perceived that they needed more control while in the projects that did deploy SAQ, respondents felt they had sufficient control. This observation reflects the reality, that the projects that deployed SAQ had better control as indicated by all measures.

It was observed that people in different roles have different perceptions of culture, as this is influenced by their responsibilities and work practices. This confirmed the expectation that a larger team of respondents is needed to achieve a reliable view of cultural orientation on any one project.

A significant difference was observed between the perceptions of culture on the collaborate-compete axis between Intervention Group PMs and PEs. It is postulated that this is most likely be due to the difference in the roles of the respondents. Nevertheless, this is considered to be a significant difference that is worthy of further research.

Finally, there was no significant difference in the safety performance of the 2 groups, though the overall rate for each group was disproportionately influenced by a small number of projects that had high to very high incident rates.

This work is a first step in the assessment of these critical correlations and shows the way forward towards improved project culture and outcomes. This includes (1) studying the impact of SAQ on outcomes across a company's different business units; and (2) understanding the factors that improve leadership engagement and operational adoption of SAQ. To facilitate this, the authors recommend: (a) implementing Quinn Survey throughout project's milestones; (b) performing cause-mapping to identify successful best practices and the upstream impacts; and (c) connecting findings back to how project teams operationalized the SAQ framework to better support underperforming business units. Further investigation is planned to study the impact of project delivery type, contract type, and leadership style and experience with repeat customers, and staffing on implementing SAQ.

\section{LIMITATIONS}

This study reports an early-stage investigation of the impact of SAQ on project outcomes. The number of projects included in this study is relatively small (22 projects), and future research is proposed to validate this study's findings and to better understand the impact of SAQ on project performance. While the results indicate a compelling case for implementing SAQ systems such as this in construction, it is important to recognize this study's limitations. It was not possible to characterize the projects in terms of many significant and important parameters such as team leadership, team experience, client culture and experience, contract type and maturity of SAQ implementation.

\section{REFERENCES}

Alarcon, L. F., and Mardones, D. A. (1998). "Improving the Design-Construction Interface."

Bertelsen, S. (2003). "Complexity - Construction in a New Perspective.” International Group of Lean Construction, 12.

Cameron, K. S., and Quinn, R. E. (2011). "The competing values culture assessment: A Tool from the Competing Values Product Line.” Wiley, (March), 1-14. 
Gargione, L. A. (1999). "Using Quality Function Deployment (Qfd) in the Design Phase of an Apartment Construction Project." 7th Annual Conference of the International Group for Lean Construction, (55), 357-368.

Love, P. E. D. (2002). "Influence of Project Type and Procurement Method on Rework Costs in Building Construction Projects." Journal of Construction Engineering and Management, 128(1), 18-29.

Love, P. E. D., Matthews, J., and Fang, W. (2020). "Rework in Construction: A Focus on Error and Violation." Journal of Construction Engineering and Management, 146(9), 06020001.

Love, P. E. D., Teo, P., Morrison, J., and Grove, M. (2016). "Quality and Safety in Construction: Creating a No-Harm Environment." Journal of Construction Engineering and Management, 142(8), 05016006.

Marosszeky, M., and Thomas, R. (2002). "Quality management tools for lean productionmoving from enforcement to empowerment." 10th Annual Conference - International Group for Lean Construction (IGLC-10), 61(2), 1-13.

Saurin, T. A., Rooke, J., Koskela, L., and Kemmer, S. (2013). "Guidelines for the management of complex socio-technical systems: An exploratory study of a refurbishment project." 21 st Annual Conference of the International Group for Lean Construction 2013, IGLC 2013, 915-924. 